\title{
Analysis of Instrument Approaches to GA Aerodromes in the World
}

\author{
Jakub Kraus \\ ATM Systems Laboratory, \\ Department of Air Transport, Faculty of Transportation \\ Sciences, Czech Technical University \\ Horská 3, Praha 2, 128 03, Czech Republic \\ e-mail: kraus@fd.cvut.cz
}

\begin{abstract}
This article deals with the exploration of GA aerodromes around the world that meet the defined input conditions of maximal $1,500 \mathrm{~m}$ long runway and the existence of straight-in instrument approach. These aerodromes are analysed from different perspectives of runway equipment with respect to the various types of published approach.
\end{abstract}

Keyword - General Aviation, Aerodrome, Straight-in Approach, nonprecision approach, runway lighting

\section{INTRODUCTION}

General aviation (GA) is in the number of aircraft the largest in the entire aviation, but it is ranked as the third in the last place after the military and civil aviation. At present, however, the pressure from representatives of general aviation intensifies, and it is needed to count with it when changes are made in the airspace.

Battles between the groups are to be found even inside GA. They are caused by the collisions between the views and demands of flying under IFR and VFR, which may seem absurd given the completely different weather conditions for flights, but to ensure the safety of IFR flights is necessary to allocate a portion of airspace, which in turn can act as a barrier for VFR flights.

The expansion of GA in Europe is inevitable as is the rising demands to create new instrument procedures at noninstrument aerodromes. But for this aerodromes is for the creation, implementation and approval of such procedures quite costly, mostly in terms of aerodrome infrastructure, which is necessary to have or to be built at the aerodrome. Thus was created the list of aerodromes and its infrastructure compared to the used instrument approach system.

\section{SELECTION OF AERODROMES}

Due to the requirements for the introduction of instrument approaches to the still non-instrument GA aerodrome in this analysis was set a limit of 1500 meters for runway length, which defines "small" aerodrome. It was also necessary to choose only aerodromes with published straight-in approach, which is what you want for IFR operations and enables significantly lower minimum descent height, respectively decision height. The choice the aerodromes have been used states with well-developed GA, such as Australia, New

\author{
Vladimír Němec \\ Department of Air Transport, \\ Department of Air Transport, Faculty of Transportation \\ Sciences, Czech Technical University \\ Horská 3, Praha 2, 128 03, Czech Republic
}

Zealand and Canada and all States under the supervision of EUROCONTROL

\section{RESULTS}

The number of approaches for subsequent analysis is 768 This number could be higher, but the runways that have approach which used the same system on both ends of the runway and have same light equipment are considered only from runway end with lower $\mathrm{OCH}$.

\section{A. Physical characteristics of the runways}

For comparison of the different runways were chosen three parameters namely length, width and surface.

At present, it is almost unthinkable that in the Europe could be instrument approach to runway with another surface than concrete or asphalt. The exception in the analysed aerodromes forms one aerodrome in Greenland (outside Europe, but in the scope of EUROCONTROL), one in Ukraine and two in the United Kingdom. However, in the remaining three analysed countries is quite common that the runway surface is gravel, grass or dirt.

TABLE I. RUNWAYS LENGTH

\begin{tabular}{|l|r|r|}
\hline Runway Length & Number & Percent \\
\hline up to 300m & 1 & 0,13 \\
\hline $301-600 \mathrm{~m}$ & 1 & 0,13 \\
\hline $601-900 \mathrm{~m}$ & 53 & 6,90 \\
\hline $901-1200 \mathrm{~m}$ & 327 & 42,58 \\
\hline $1201-1500 \mathrm{~m}$ & 386 & 50,26 \\
\hline
\end{tabular}

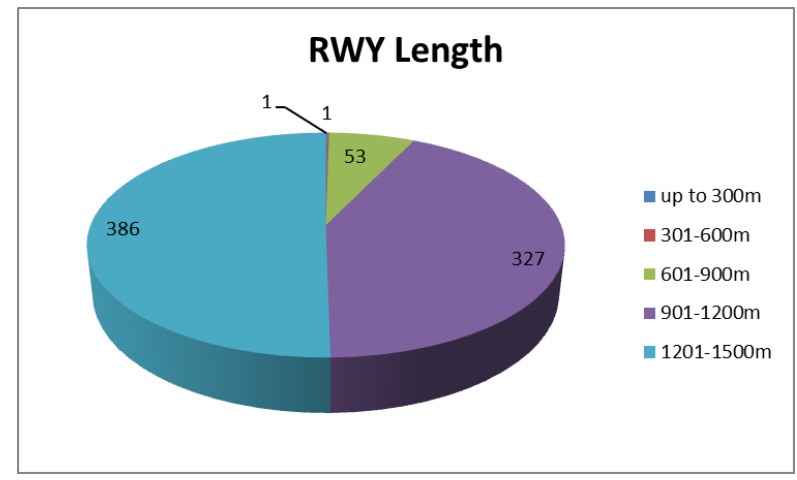

Figure 1. Runway Length 
TABLE II. RUNWAY WIDTH

\begin{tabular}{|l|r|r|}
\hline Runway Width & Number & Percent \\
\hline up to $10 \mathrm{~m}$ & 2 & 0,26 \\
\hline $11-20 \mathrm{~m}$ & 43 & 5,60 \\
\hline $21-30 \mathrm{~m}$ & 619 & 80,60 \\
\hline over 30m & 104 & 13,54 \\
\hline
\end{tabular}

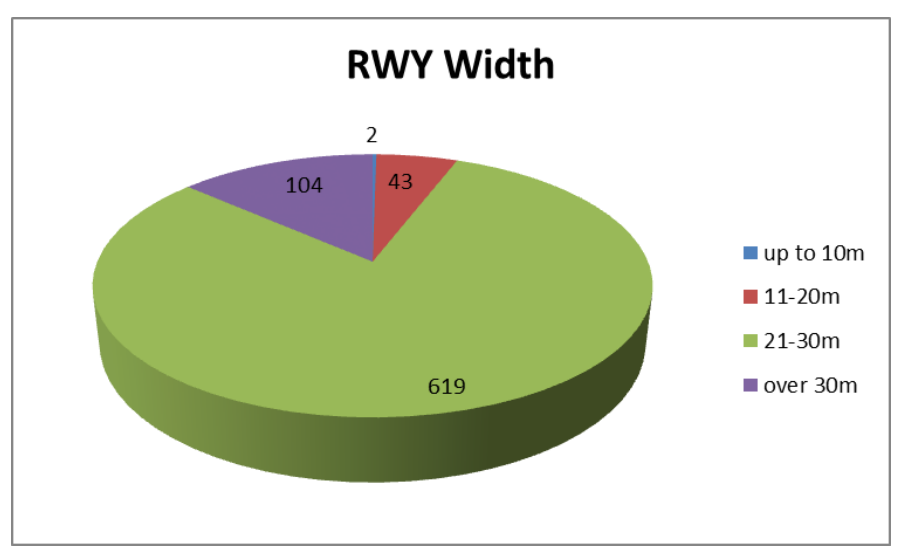

Figure 2. Runway Width

TABLE III. RUNWAY SURFACE

\begin{tabular}{|l|r|r|}
\hline Runway Surface & Number & Percent \\
\hline Dirt & 3 & 0,39 \\
\hline Crushed rock & 8 & 1,04 \\
\hline Sand & 2 & 0,26 \\
\hline Gravel & 104 & 13,54 \\
\hline Grass & 7 & 0,91 \\
\hline Asphalt/Concrete & 644 & 83,85 \\
\hline
\end{tabular}

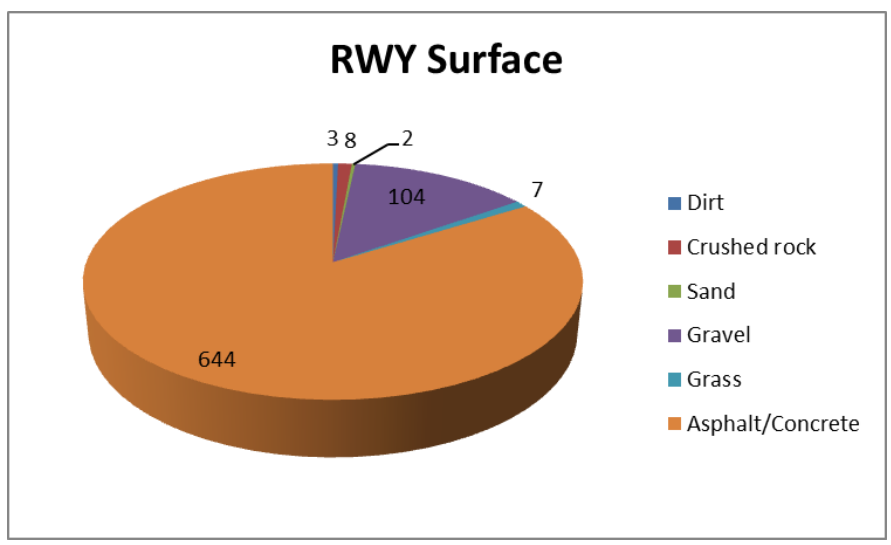

Figure 3. Runway Surface

Comparison of physical parameters of runways has been added here only for information purposes, since the size of the RWY only affects the category of operated aircraft. But from these comparisons could be concluded needed equipment of aircraft "categories" for IFR flying.

\section{B. Runway lights}

Given that aviation regulations allow IFR traffic on runways without lighting systems, it is interesting to see how this option is used by individual aerodromes. But it is necessary to realize that the minimum RVR at which it is still possible to land increases along with reducing runway lights, which also reduces the possibility of sighting the runway (or light navigation aids) at the minimum descent altitude, respectively decision height. This limits the use of instrument approach.

Runway lights have the vast majority of analysed aerodromes, but approach slope/path lights has only two thirds of aerodromes and approach lighting system has only $40 \%$ of the runways.

TABLE IV. RUNWAY LIGHTS

\begin{tabular}{|l|r|l|}
\hline Runway Lights & Number & Percent \\
\hline yes & 749 & 97,53 \\
\hline no & 19 & 2,47 \\
\hline
\end{tabular}

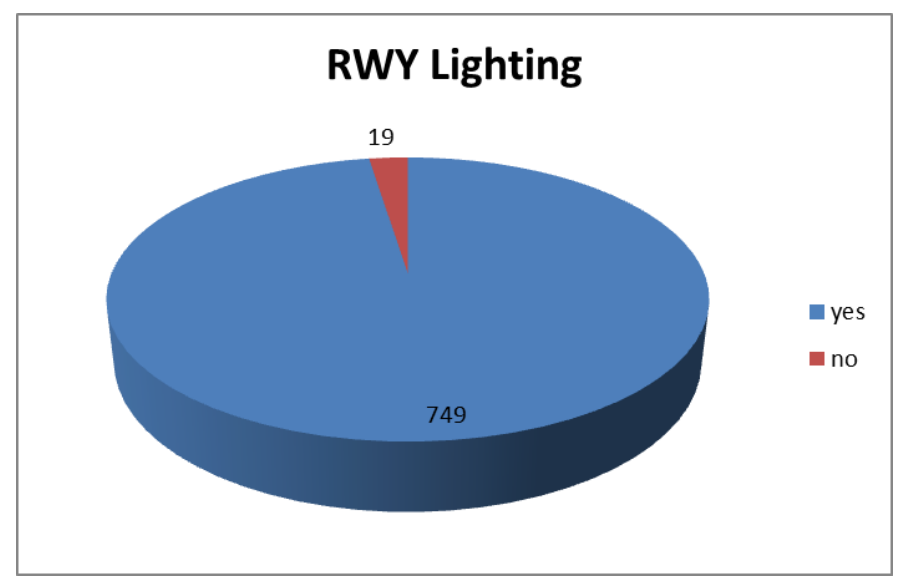

Figure 4. Runway Lights (minimum is RWY edge lights)

TABLE V. APPROACH SLOPE/PATH LightS

\begin{tabular}{|l|r|r|}
\hline $\begin{array}{l}\text { Approach } \\
\text { Slope/Path Lights }\end{array}$ & Number & Percent \\
\hline nothing & 257 & 33,46 \\
\hline AVASIS & 10 & 1,30 \\
\hline AT-VASIS & 1 & 0,13 \\
\hline T-VASIS & 2 & 0,26 \\
\hline VASIS & 23 & 2,99 \\
\hline APAPI & 101 & 13,15 \\
\hline PAPI & 310 & 40,36 \\
\hline PLASI & 63 & 8,20 \\
\hline unknown & 1 & 0,13 \\
\hline
\end{tabular}




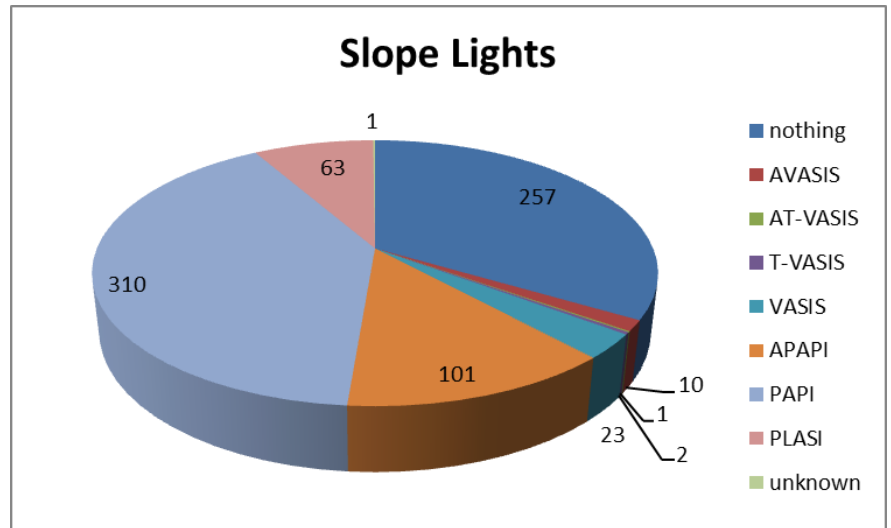

Figure 5. Approach Slope/Path Lights

TABLE VI. APPROACH LIGHTING

\begin{tabular}{|l|r|r|}
\hline Approach Lighting & Number & Percent \\
\hline nothing & 305 & 39,71 \\
\hline RWY ident & 153 & 19,92 \\
\hline ODALS & 40 & 5,21 \\
\hline MALSR & 2 & 0,26 \\
\hline CL & 10 & 1,30 \\
\hline SALS & 90 & 11,72 \\
\hline SALS + ident & 23 & 2,99 \\
\hline CL + RWY ident & 21 & 2,73 \\
\hline Lead-in & 14 & 1,82 \\
\hline Cat I & 28 & 3,65 \\
\hline MALSF & 1 & 0,13 \\
\hline yes & 5 & 0,65 \\
\hline CL/XBAR & 75 & 9,77 \\
\hline unknown & 1 & 0,13 \\
\hline
\end{tabular}

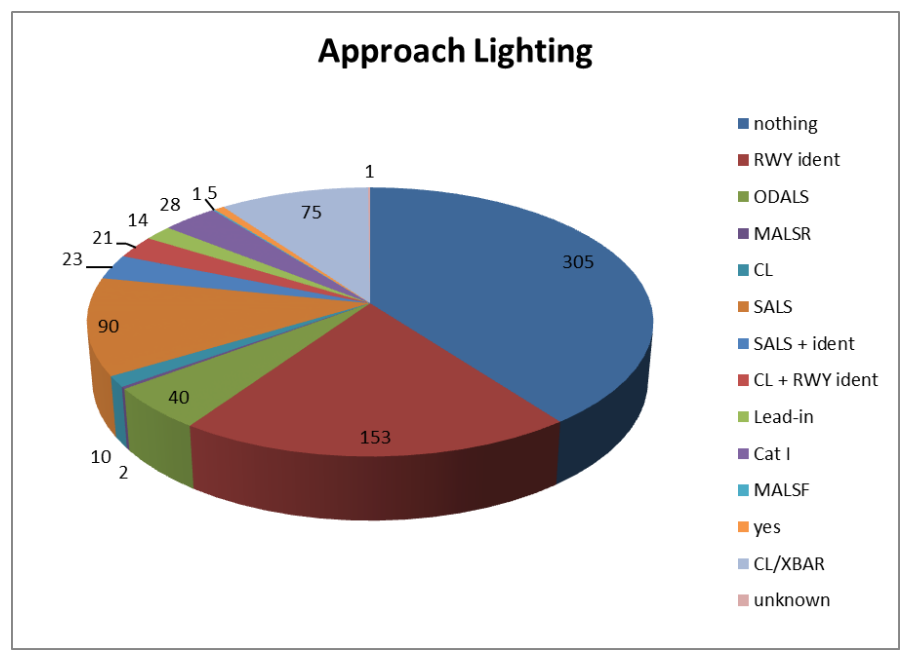

Figure 6. Approach Lighting System

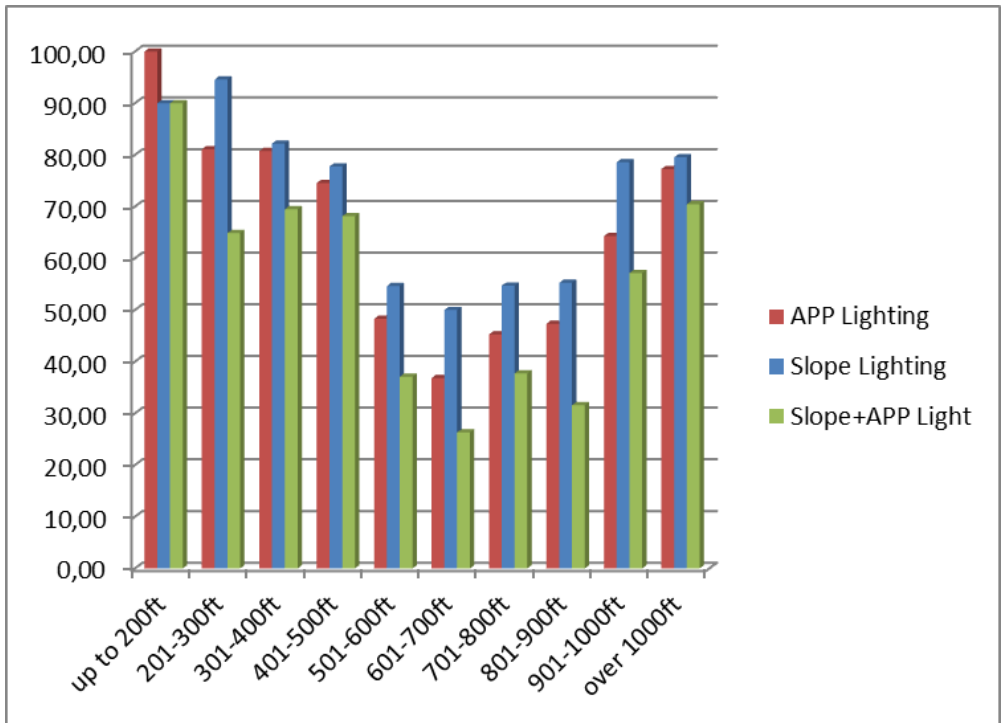

Figure 7. Percentage of Lighting Systems in Comparison to RWY OCH

\section{The Presence of ATS}

Current situation in the Czech Republic shows a reduction in requirements for aerodromes with IFR procedure. The main one is the abolition of the requirement to have at this aerodrome ATC and around the aerodrome controlled airspace. The following table therefore shows the number and percentage of different types of airport services.

TABLE VII. The PRESENCE OF ATS

\begin{tabular}{|l|r|r|}
\hline ATS Type & Number & Percent \\
\hline AFIS & 222 & 28,91 \\
\hline APRT RDO & 53 & 6,90 \\
\hline Unicom & 103 & 13,41 \\
\hline TFC & 95 & 12,37 \\
\hline Radio & 52 & 6,77 \\
\hline nothing & 110 & 14,32 \\
\hline TWR & 133 & 17,32 \\
\hline
\end{tabular}

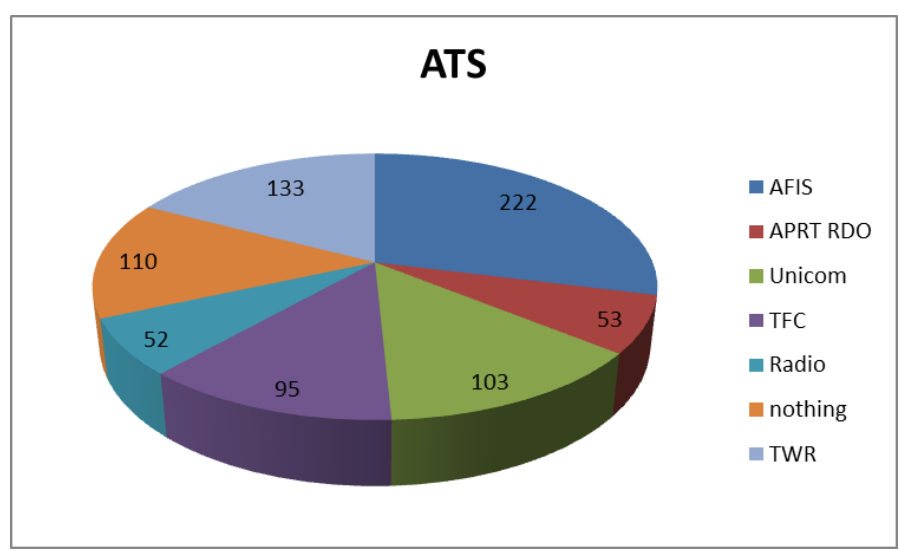

Figure 8. The Presence of ATS 


\section{Approach systems}

The type of approach system determines the approach minima for the runway. In recent years, the effort is to move from ground-based to space-based navigation systems and therefore to some type of GNSS.

TABLE VIII. ThE USAGE OF APPROACH SySTEMS

\begin{tabular}{|l|r|r|}
\hline Approach System & Number & Percent \\
\hline VOR & 21 & 2,7 \\
\hline DVOR & 1 & 0,1 \\
\hline VOR/DME & 29 & 3,8 \\
\hline GNSS & 72 & 9,4 \\
\hline IGS & 2 & 0,3 \\
\hline ILS & 19 & 2,5 \\
\hline ILS/DME & 6 & 0,8 \\
\hline GPS & 2 & 0,3 \\
\hline LNAV & 233 & 30,3 \\
\hline LNAV/VNAV & 17 & 2,2 \\
\hline LPV & 21 & 2,7 \\
\hline LOC & 37 & 4,8 \\
\hline LOC/DME & 23 & 3,0 \\
\hline LOC(BC)/DME & 3 & 0,4 \\
\hline LOC/NDB & 1 & 0,1 \\
\hline 2NDB & 3 & 0,4 \\
\hline
\end{tabular}

\section{APP system}

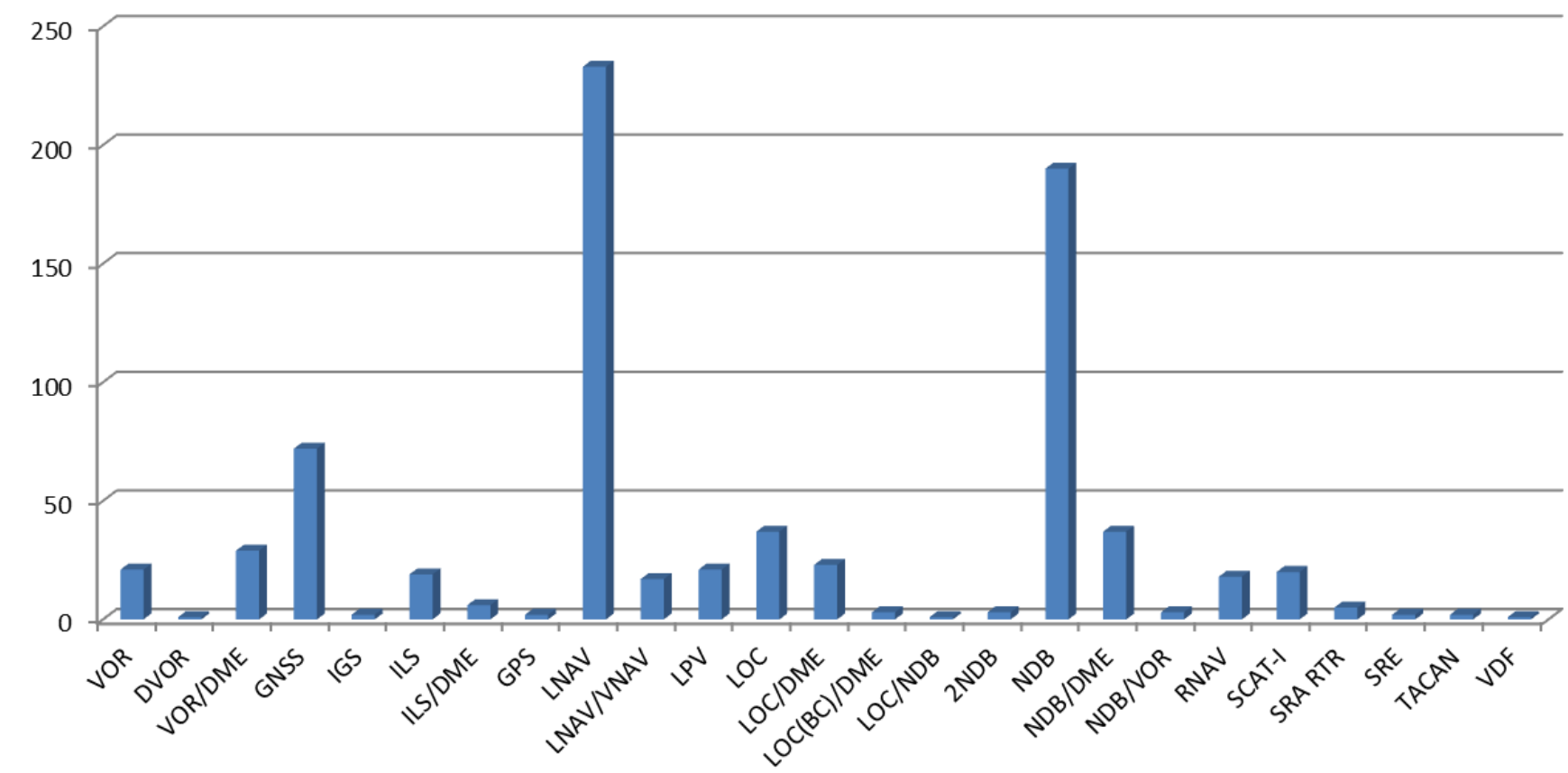

Figure 9. Approach systems at analysed aerodromes 
E. Approach systems and RWY lighting by the analysed states

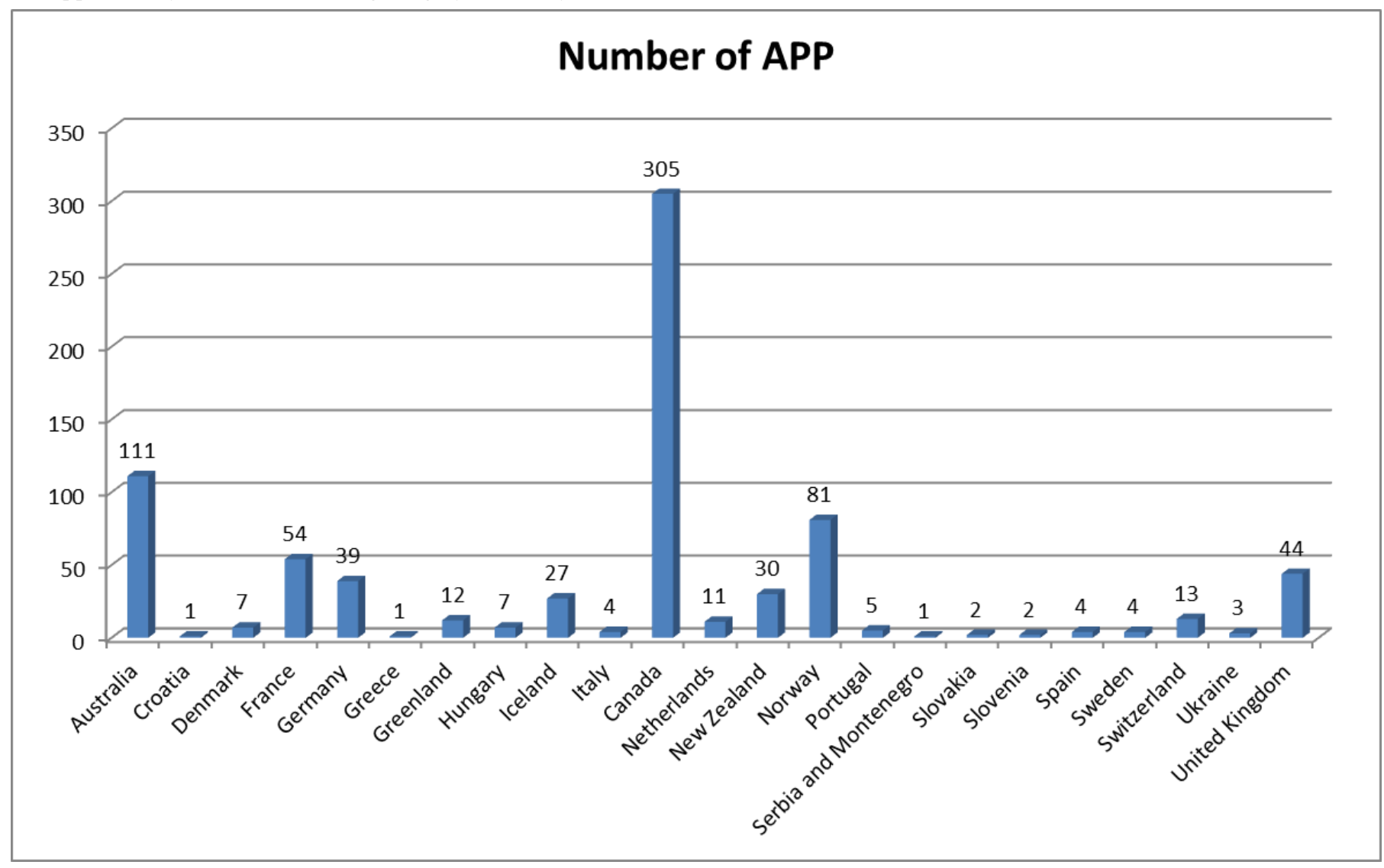

Figure 11. Approach systems by states

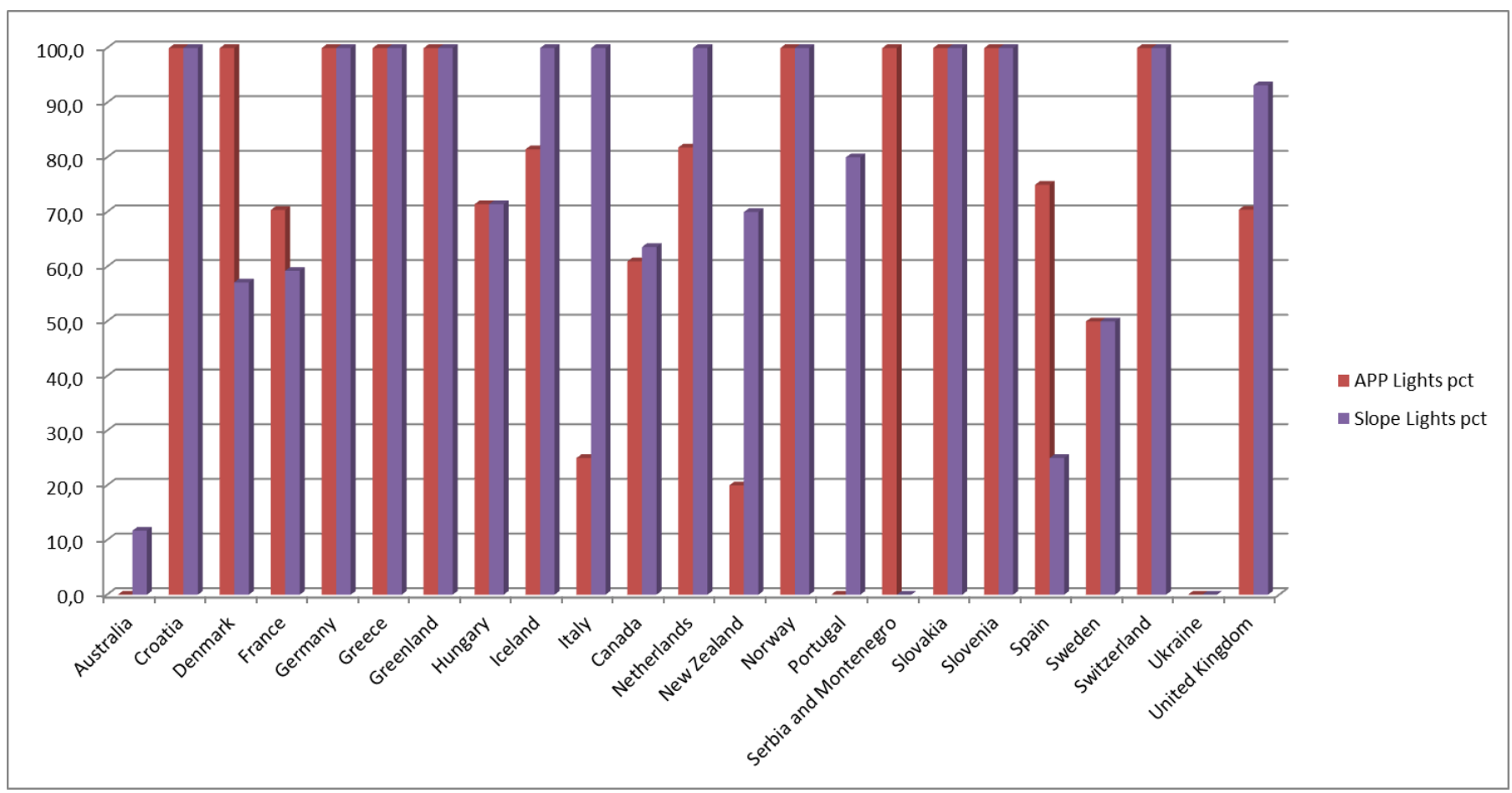

Figure 12. Percentage of approach lighting system and approach slope/path lighting system on the runways of analysed aerodromes by states 


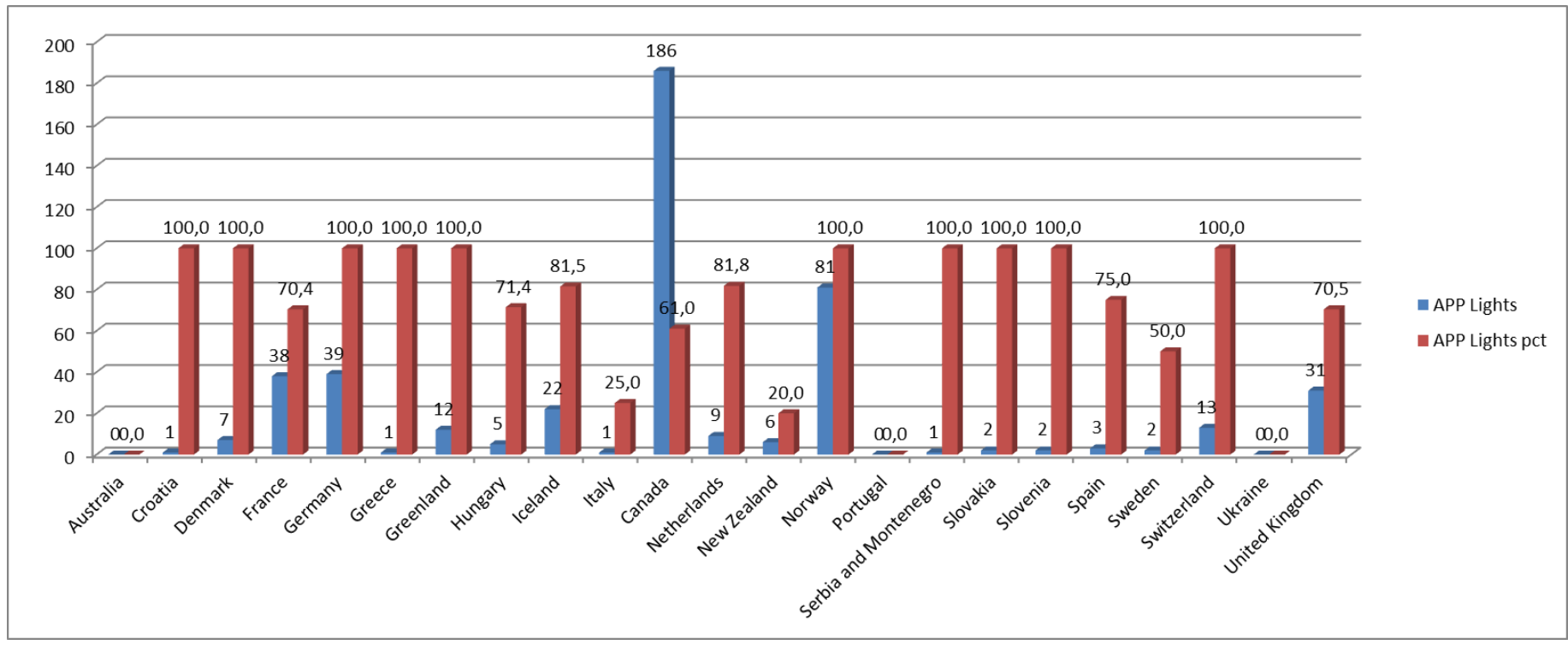

Figure 13. Absolute and relative numers of approach lighting system on the runways of analysed aerodromes by states

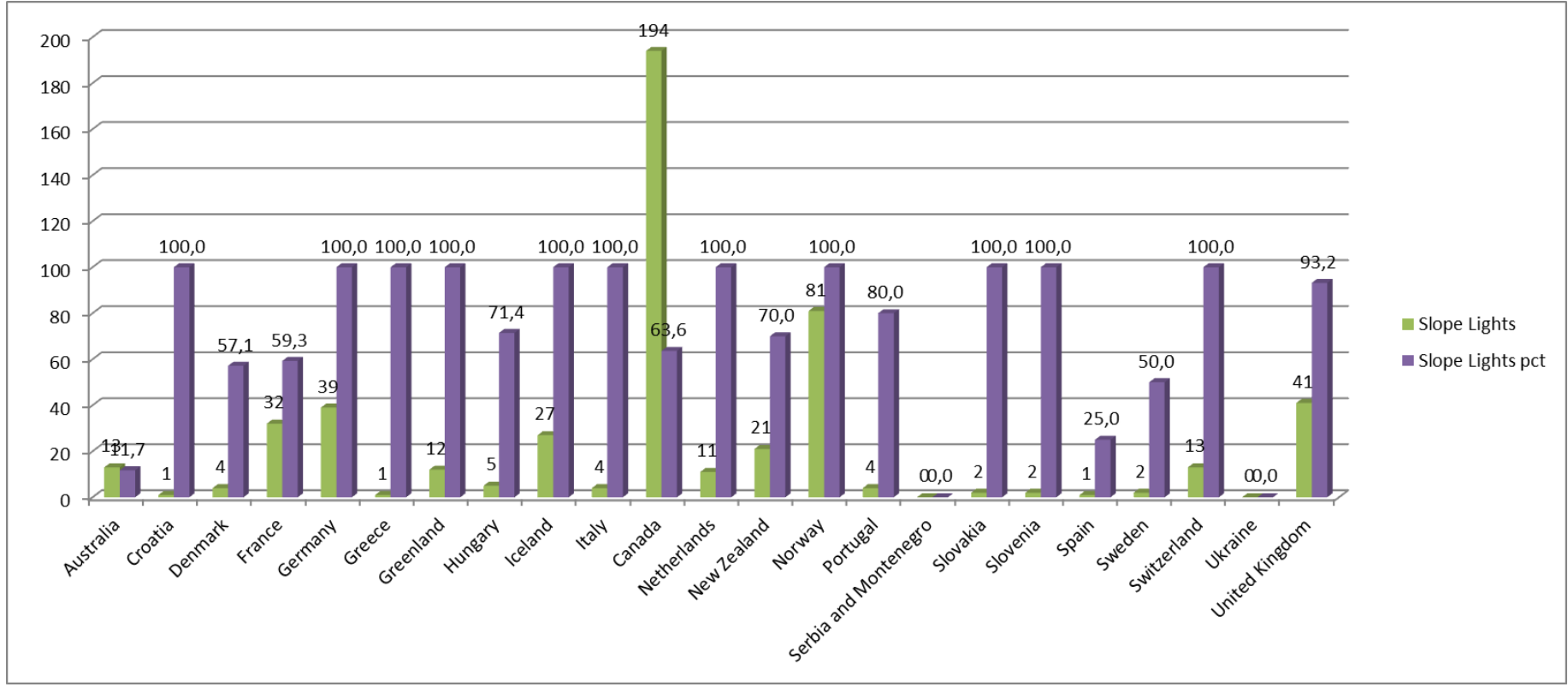

Figure 14. Absolute and percentage numbers of approach slope/path lighting system on the runways of analysed aerodromes by states

\section{CONCLUSION}

The aerodromes analysis shows that the introduction of a new instrument approach to the aerodrome is possible from the regulation point of view. Instrument approaches in the world are used on aerodromes, which are from a European, respectively Czech perspective completely incapable.

This situation exists certainly due to the different geographical structure of states and therefore highly developed small aviation. To that is also related the perception of safety and respect for the regulation (compliance with regulations), the so-called safety culture. Thanks to its development is probably possible to find specialties in the Aeronautical Information Publication such as a railway across the runway at the aerodrome in Gisborne, New Zealand. (See Fig. 15)
From the perspective of regulations and practice it is possible to introduce instrument approach to any aerodrome in the world. It depends only on the approach of the supervisory authorities; if they are willing to give responsibility to aircraft pilots, or whether they want to have a properly treated all possible cases that may happen. The first approach is useful for airspace users, but in the event of an incident, or worse, an accident can be blamed the authority as indirect cause. In the second case should not happen any dangerous situation, since they are all protected by regulations, but they are also a limiting factor that may be violated. In this case are authorities are out of guilt when some situation with impact on safety take place. 


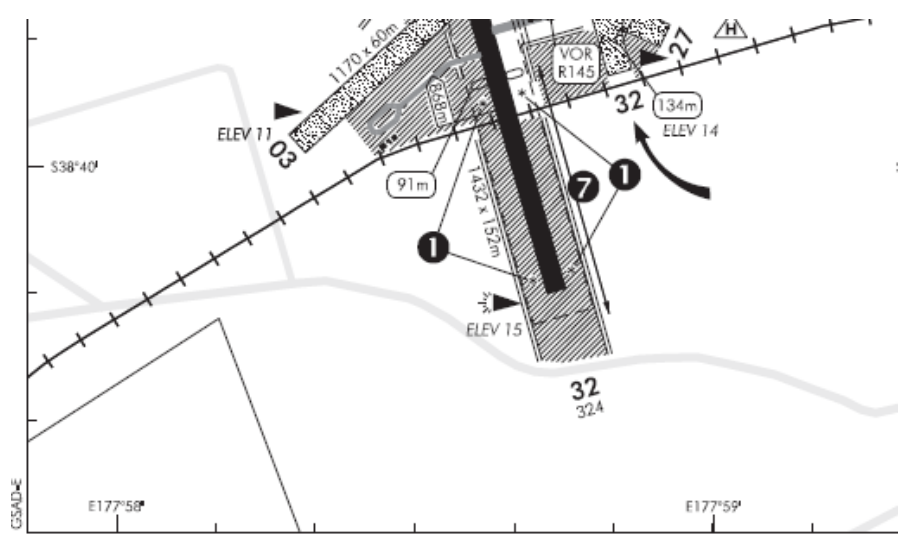

0 RWY/Railway signal lights. Refer to Gisborne operational signal lights chart.

2. RWY 14/32 full length (RWY extension open) available under the following conditions: - ATS on duty, or an authorised person is in attendance, or runway/railway signals are - Aircraft is RTF equipped.

3. Operations when RWY extension closed.

During these periods trains have the right-of-way and may operate at any time.

Figure 15. The map section of the AIP New Zealand - railway across the runway

\section{ACKNOWLEDGEMENTS}

This paper was supported by the Grant Agency of the Czech Technical University in Prague, grant No. SGS14/212/OHK2/3T/16.

\section{REFERENCES}

[1] EUROCONTROL. EAD Basic. [online]. [cit. 2014-02].

Available at:

<https://www.ead.eurocontrol.int/publicuser/public/pu/logi n.jsp>

[2] AIP ČR [online]. Available at: $<$ http://lis.rlp.cz/ais_data/www_main_control/frm_cz_aip.ht $\mathrm{m}>$

[3] AIP New Zealand [online]. Available at: $<$ http://www.aip.net.nz/Home.aspx>

[4] AIP New Zealand [online]. Available at: <https://www.airservicesaustralia.com/aip/aip.asp>

[5] IVAO. IFR Airport Charts (Canada Air Pilot - CAP) [online]. [cit. 2014-02]. Available at: <http://www.ivao.ca/charts/cap> 